\title{
A prospective hospital study of alcohol use disorders, comorbid psychiatric conditions and withdrawal prognosis
}

\author{
Philippe Nubukpo ${ }^{1,2,3}$, Murielle Girard ${ }^{2 *}$, Jean-Marie Sengelen ${ }^{4}$, Sophie Bonnefond ${ }^{5}$, Aurélien Varnoux 5 , \\ Benoît Marin ${ }^{3}$ and Dominique Malauzat ${ }^{2}$
}

\begin{abstract}
Background: The objective of this study was to describe the profile and alcoholic status of a population with alcohol use disorders (AUD) requesting help from a psychiatric hospital to stop drinking, as well as their clinical outcome and care consumption over the 2 years following the request.

Methods: The visits were conducted at baseline (M0) and at 6, 12, 18 and 24 months (M6, M12, M18, M24). Demographic, clinical and psychometric data [Beck Depression Inventory (BDI), AUDIT questionnaire, Global Assessment of Functioning (GAF) scale], and information regarding the use of psychiatric care and therapeutics were collected.

Results: The 330 subjects included were mostly male, aged $45.2 \pm 10.2$ years with an employment rate of $55.4 \%$, living alone (69.1\%), with a psychiatric comorbidity (60.9\%), especially depressive, and with few somatic complications. Their global functioning was poor (GAF score $49.14 \pm 15.6$ ), and less than $10 \%$ were addicted to another substance. The abstinence rate at 24 months was $41.4 \%$, but only $23 \%$ (20) abstained continuously between M0 and M24, and $66.7 \%$ (58) intermittently. The likelihood of abstinence at M24 was greater for females aged over 60 years. The BDI score decreased significantly between $\mathrm{M0}$ and $\mathrm{M} 24$. In all, $56.2 \%$ of the participants were re-hospitalized after weaning, but were not integrated in long-term medical care.

Conclusions: Abstinence after alcohol withdrawal fluctuated over time indicating the need for long-term support. The treatment of AUD should not target total, continuous abstinence. Prognostic profiles combining socio-demographic, clinical and biological indicators must be established.
\end{abstract}

Keywords: Alcohol, Psychiatry, Comorbidity, Withdrawal, Abstinence, Psychiatric care

\section{Background}

Over the past few centuries, the French society has treated alcoholism as an affliction in a complex context combining an ancestral way of life with divergent economic, social, political and health interests. Alcohol use disorder (AUD) is a major direct and indirect cause of high rates of mortality and morbidity worldwide [1].

The lifetime prevalence of AUD is estimated to be between 7 and $12.5 \%$ in most Western countries [2, 3].

\footnotetext{
*Correspondence: murielle.girard@ch-esquirol-limoges.fr

${ }^{2}$ Département de Recherche et Développement (DRD), Centre

Hospitalier Esquirol, 87025 Limoges, France

Full list of author information is available at the end of the article
}

In primary health care (general practice) in France, the prevalence of problematic alcohol use is estimated to be between 5.2 and $7.9 \%$, but may reach $11 \%$ for risky or dangerous alcohol consumption $[4,5]$.

Long-term mortality in alcohol-dependent subjects is three to five times higher than the theoretical mortality calculated for non-alcohol-dependent subjects, and inhospital mortality caused by health problems linked to alcohol abuse is about $20 \%$ in subjects hospitalized for psychiatric disorders or other diseases [5-9]. The social costs of AUD are high in France and throughout Europe, due to accidents, absenteeism, direct and indirect medical costs and negative impact on the family environment and the living conditions [10-12]. 
Comorbidity with psychiatric problems is associated with a poorer prognosis of both conditions due to diagnostic problems and difficulties with the care pathway [13-15].

According to the World Health Organization (WHO), comorbidity is defined in psychiatry as "the occurrence, in a given person, of both a problem due to the consumption of a psychoactive substance and another psychiatric problem". Comorbidity, or dual diagnosis, is a major public health issue for several reasons. The addition of an addictive comorbidity to a psychiatric problem increases the impact of the disease on the patient and their family [16], worsens violent behavior and breakups due to mental problem [17] and increases the financial cost of the disease $[16,18]$. The health benefits of weaning patients off alcohol are recognized, but the prognosis after withdrawal of alcohol-dependent subjects with comorbid psychiatric conditions is less well understood. In particular, we know little about the abstinence profile during the months following the cessation of alcohol consumption, or the links between fluctuations in alcohol consumption during this period and clinical data and biological factors. To improve our understanding of AUD in psychiatry, we carried out a cohort study, in a French psychiatric hospital, on 330 alcohol-dependent subjects requesting assistance to stop drinking.

The aim was to establish a profile of the people concerned (those with a high probability of a dual diagnosis of AUD and a comorbid psychiatric condition) and to describe the changes in their alcohol use status over the 2 years following their withdrawal according to clinical and biological criteria, as well as their use of health-care services.

\section{Methods}

This study was carried out at Esquirol Hospital in Limoges, France, a regional public psychiatric hospital with 985 beds and the capacity to accommodate partially or fully hospitalized patients suffering from psychiatric problems and/or addiction. The frequency of AUD in the region and the consultation rates in centers specializing in alcohol-related problems (2.8 inhabitants aged between 20 and 70 years per thousand) were similar to those for the rest of France [19].

\section{Study population}

We included 330 people aged 18 years or over, presenting with AUD with dependence and requesting treatment to stop drinking during the first week of hospitalization in the hospital care units between September 2006 and September 2008. These individuals were included regardless of their mode of alcohol consumption and their psychiatric and/or somatic comorbid conditions. We did not include individuals with no fixed abode, presenting a progressive somatic condition with an estimated life expectancy shorter than 24 months, displaying noticeable alterations of cognitive function preventing the evaluations (illiteracy, dementia or moderate to severe intellectual deficiency), as evaluated by the doctor in the care unit of hospitalization.

\section{Ethics, consent and permissions}

This study was carried out in accordance with French regulations governing biomedical research and was approved by the Research Board of the French Ministry of Health, the Limousin institutional review board [Comité de Protection des Personnes qui se prêtent à une Recherche Biomédicale (CPPRB)] and the French data protection agency (CNIL).

Each participant gave an informed written consent.

\section{Study design}

We avoided interventions that would affect the participants' outcome: 6-monthly follow-up visits with no major constraints for the participants were scheduled and integrated as closely as possible in the essential care procedures already established for this type of disease.

The investigators were not given any instruction about the type of therapeutics to use during the survey (either pharmacological or non-pharmacological), because of the semi-naturalistic nature of the study. So, the participants received non-pharmaceutical support of their clinician, which consisted of a psychological/psychosocial (BRENDA type) approach. Neither cognitive behavioral therapy nor any other structured intervention was provided. The participants were thus re-evaluated every 6 months, over a period of 2 years (M0, M6, M12, M18, M24), when hospitalized or as outpatients. The various visits were carried out during a medical consultation within the framework of the standard alcohol withdrawal follow-up program. If no medical visit was scheduled for one of the time points, a research nurse contacted the participant by telephone or e-mail to schedule an appointment for a clinical evaluation and to collect the biological samples required for the study. The reasons for follow-up visits not taking place were classified as "lost to follow-up", "refusal" or "death". Participants were considered "lost to follow-up" if they could not be contacted, if they did not respond when contacted, or if they were unable to attend (e.g., unable to travel, moved home, illness). Additional efforts were made to contact participants for the final follow-up visit at 24 months (letters, telephone calls, contact made with relatives or family doctor). 


\section{Clinical, psychometric and biological measurements}

At inclusion, a clinical evaluation was carried out by the doctor of the unit in which the patient was hospitalized (the consultant doctor). The principal diagnosis and comorbid conditions were identified according to the DSM-IV-TR criteria by the same consultant doctor, together with socio-demographic data (lifestyle, marital status, professional activity, source of income, protective measures), history of psychiatric care (number of years, number of hospitalizations), psychometric data [Alcohol Use Disorders Identification Test (AUDIT), Beck Depression Inventory (BDI), Global Assessment of Functioning (GAF) scale] and current treatment. A blood sample was taken as part of routine care by the unit staff. The complete biological evaluation included measurements of mean corpuscular volume (MCV) and gamma-glutamyl transferase $(\gamma \mathrm{GT})$ activity at all follow-up visits, as well as determination of liver transaminase serum glutamate oxaloacetate transaminase (SGOT) and serum glutamic pyruvic transaminase (SGPT) activity at M0 and M24.

The data collected at the M6, M12, M18 and M24 follow-up visits were, with the exception of the psychiatric care history already recorded, almost identical to those collected at inclusion. The following information during the follow-up visits was collected: alcohol consumption status, GAF score and comorbidities if the patient saw the doctor in the frame of their usual medical care pathway. AUDIT score (at M12 and M24), duration of care received (number of days of partial or full hospitalization), outpatient follow-up (e.g., outpatient care, home visits by nurses), rate of rehospitalization after alcohol withdrawal between M0 and M24, time between therapeutic alcohol withdrawal and first care intervention were non-medical data collected by a research nurse or care staff nurses.

The AUDIT questionnaire [20] addresses current alcohol-related problems and explores behavior over the previous 12 months. Based on the total score, it is possible to classify alcohol consumers according to their type of consumption: risky consumption or use (score strictly below 7 in men, or 8 in women), misuse or harmful use (score between 7 and 12 in men, or between 8 and 11 in women) or alcohol dependence (score strictly greater than 12 in men, or 11 in women).

The 13-item Beck Depression Inventory, or BDI, was used to evaluate depressiveness [21-23]. It yields a score from 0 to 39 , which is interpreted as follows: $0-3$ : no depression; 4-7: mild depression; 8-15: medium to moderate depression; 16 and over: severe depression.

Using the Global Assessment of Functioning (GAF) scale (DSM-IV-TR axis V), clinicians can evaluate the psychological, social and professional functioning of the patient on a hypothetical continuum from full mental health (100 or optimal functioning) to disease ( 0 or completely non-functional). The evaluator should not take into account changes in functioning due to limiting physical or environmental factors.

Abstinence was determined at M6, M12, M18 and M24 using a combination of clinical and biological criteria: declaration of absence of alcohol consumption by the participant (interview with a doctor or a study nurse) and concordance between a mean corpuscular volume (MCV) below $96 \mu \mathrm{m}^{3}$ and serum $\gamma \mathrm{GT}$ activity at least half that at the time of alcohol withdrawal or below the reference value $(<52 \mathrm{IU} / \mathrm{ml}$ for men or $<32 \mathrm{IU} / \mathrm{ml}$ for women, according to analytical laboratory standards). Subjects not satisfying these criteria were considered non-abstinent. Relapse at one of the follow-up visits was determined by objective detection by the investigator, using clinical or biological means of "non-abstinence" after a period of abstinence. Abstinent subjects were those for whom abstinence was clearly established at each of the follow-up visits over the 24-month period. Intermittently abstinent subjects at M24 were defined as subjects for whom alcohol consumption was detected during at least one of the follow-up visits, but with abstinence at M24.

To determine the care pathway, the number of days of partial or full hospitalization was extracted from the computerized patient data records, which included medical and paramedical interventions, the number of days in hospital for each individual seen at the hospital and, depending on the information provided by the participants, admissions to other psychiatric or non-psychiatric facilities. The cumulative duration of these sequences was calculated in days for the 24-month follow-up period. Outpatient interventions were also recorded.

\section{Statistical analysis}

The results are presented as means \pm standard deviations for continuous quantitative variables (age, BDI score, AUDIT score, GAF score, $\gamma$ GT levels, MCV, SGOT and SGPT levels, number of care interventions, duration of care sequences, etc.) and as percentages and absolute numbers for qualitative variables (sex, abstinence status, lifestyle, social welfare benefits, type of diagnosis, presence of comorbid conditions, socio-demographic data). The nonparametric Kruskall-Wallis test (or the MannWhitney test for pairwise comparisons) was used to compare the distributions of quantitative variables between groups, as these variables were not normally distributed. Differences in data between M0 and the other follow-up visits were compared using nonparametric paired Wilcoxon tests.

Student's $t$ test was used to compare quantitative variables (mean scores on the Beck and AUDIT scales) between subgroups, because these variables followed a 
normal distribution. Pearson's $\chi^{2}$ test was used to compare qualitative variables between subgroups, or Fisher's exact test if the number of values in each cell was too small. We used Systat version 11 for Windows and $p<0.05$ was considered to be significant.

We carried out a logistic regression analysis to identify the variables associated with abstinence, with the aim of determining the reasons for alcohol abuse. We carried out an initial series of univariate logistic regression analyses. The variables considered in the univariate analysis were diagnostic category at M0, type of care (outpatient, hospitalization), age group $(<30,30-60,>60$ years), sex (male/female), living alone (yes, no) and on social welfare benefits (yes/no). The variables with a $p$ value less than 0.2 in the univariate analysis were included in a multivariate logistic model. Qualitative variables were integrated in the model without modification. Prior checks were carried out for the quantitative variables: if the odds ratio was demonstrated to be log-linear, then these variables were included in the model without modification; otherwise, they were categorized by quartile. The initial multivariate model was simplified by a stepwise backward elimination method, such that the final model included only variables significantly associated with the variable to be explained. We checked that no confounding occurred during the stepwise elimination procedure. Following the univariate analysis on the study population of 246 people, the five variables retained for the multivariate analysis were care category, age group, sex, living alone (yes, no) and on social welfare benefits category. This part of the analysis was carried out using SAS software (SAS V9.3, SAS Institute, Cary, NC).

\section{Results}

\section{General description of the cohort at inclusion}

Socio-demographic, clinical and biological data for the participants at inclusion are summarized in Table 1.

The study population consisted largely of young men, mostly living alone $(69.1 \%)$. About one-third of the participants declared living with someone else as a couple. Just over half the participants were employed, and most of their income came from private sources rather than from benefits.

In terms of addictive comorbid conditions, smoking was highly prevalent. In contrast, few subjects were dependent on another psychoactive substance: $2.5 \%$ were dependent on cannabis, $0.8 \%$ on opiates and $0.4 \%$ on cocaine.

In terms of psychiatric comorbid conditions, depression was the most frequent comorbid condition $(p<0.001)$, followed by psychotic and anxious disorders.

According to the AUDIT scores, seven had a score of 7 or below. Clinical examinations confirmed alcohol
Table 1 Characteristics of the population at inclusion

\begin{tabular}{|c|c|}
\hline$N=330$, unless otherwise indicated & Mean \pm SD $(n)$ or $\%(n)$ \\
\hline Age (years) & $45.2 \pm 10.2$ \\
\hline Sex-ratio (male/female) & $3.6(258 / 72)$ \\
\hline Single/divorced/widowed (324) & $69.1 \%(224)$ \\
\hline \multicolumn{2}{|l|}{ Lifestyle (324) } \\
\hline Couple & $31.5 \%(102)$ \\
\hline Living alone & $39.1 \%(127)$ \\
\hline Other (family, friends...) & $29.4 \%(97)$ \\
\hline With a professional activity & $55.4 \%(174)$ \\
\hline \multicolumn{2}{|l|}{ Resources (327) } \\
\hline Own or from family & $67.9(222)$ \\
\hline Social & $32.1(105)$ \\
\hline Smokers & $80.2 \%(186)$ \\
\hline With psychiatric co-morbidity & $60.9 \%(200)$ \\
\hline \multicolumn{2}{|l|}{ Type of psychiatric comorbidity } \\
\hline None & $39.1 \%(129)$ \\
\hline Dementia & $1.5 \%(5)$ \\
\hline Psychosis & $4.6 \%(15)$ \\
\hline Mood and affective disorder & $30.6 \%(101)$ \\
\hline Anxiety disorder & $5.5 \%(18)$ \\
\hline Personality disorder & $26.1 \%(87)$ \\
\hline With somatic comorbidity & $7.6 \%(25)$ \\
\hline Global Assessment of Functioning & $49.14 \pm 15.60$ \\
\hline AUDIT (312) & $26.9 \pm 7.7$ \\
\hline Risk use (score $\leq 7$ ) & $2.2(7)$ \\
\hline Harmful use $(7<$ score < 13) & $2.2(7)$ \\
\hline Dependence (score $\geq 13$ ) & $95.5(298)$ \\
\hline BDI score (308) & $13.5 \pm 7.1$ \\
\hline \multicolumn{2}{|l|}{ BDI categories } \\
\hline Absent & $5.8(18)$ \\
\hline Slight & $16.2(50)$ \\
\hline Moderate & $41.6(128)$ \\
\hline Severe & $36.4(112)$ \\
\hline $\operatorname{MCV}\left(\mu m^{3}\right)$ & $97.9 \pm 6.2$ \\
\hline$\%>$ normal values $(n)$ & $55.9(181)$ \\
\hline SGOT (UI/L) & $47.4 \pm 53.5$ \\
\hline$\%>$ normal values $(n)$ & $39.3(129)$ \\
\hline SGPT (UI/L) & $42.5 \pm 41.5$ \\
\hline$\%>$ normal values $(n)$ & $41.5(136)$ \\
\hline GGT (UI/L) (mean \pm SD) & $222.7 \pm 408.2$ \\
\hline$\%>$ normal values $(n)$ & $61.6(202)$ \\
\hline \multicolumn{2}{|l|}{ Current psychotropic treatment } \\
\hline Neuroleptics & $14.2 \%(47)$ \\
\hline Atypical antipsychotics & $14.5 \%(48)$ \\
\hline Thymoregulators & $7.8 \%(26)$ \\
\hline Antidepressants & $52.7 \%(174)$ \\
\hline Anxiolytics & $90(297)$ \\
\hline Benzodiazepines & $88.4 \%$ (292) \\
\hline Related to benzodiazepines & $23.0 \%(76)$ \\
\hline
\end{tabular}

AUDIT alcohol use disorder identification test, $B D I$ Beck Depression Inventory, GGT gamma-glutamyl transferase, $M C V$ mean corpuscular volume, SGOT serum glutamate oxaloacetate tranasminase, SGPT serum glutamic pyruvic transaminase 
dependence in these 14 cases. Mean daily consumption (TAC) was high, $34.6 \%$ (108 people) of the participants declared consuming at least 10 units per day and $51.6 \%$ (161 people) 5-8 units per day. Similarly, the number of heavy drinking days corresponded to "almost every day" for $51 \%$ of the participants (159 people). The mean BDI score indicated moderate to severe depressiveness for this population, with a total proportion of $78 \%$ of those included presenting a high score for depression.

Only a few somatic comorbid conditions were reported: ankylosing spondylitis (3 cases), esophagus, stomach and duodenum diseases (4), respiratory diseases (5), liver disease (1), viral infections (3), heart disease (3), metabolic disorders (2), epilepsy (2), breast cancer (1) and other physically disabling conditions (4 cases).

The values for biological markers of liver function and alcohol dependence ( $\gamma \mathrm{GT}$ and MCV) were both above the normal range (reference values) for $42 \%$ of the participants (136 people). The values for these two markers were in the normal range for $24.7 \%$ of the participants (80 people).

Regarding drug therapy, the most frequently prescribed drug at inclusion was benzodiazepine, followed by antidepressants, which were taken by more than half the participants.

\section{Changes over the $\mathbf{2 4}$ months following the request for help to stop drinking and abstinence}

Data were collected for about half the patients at the M6, M12 and M18 visits (Table 2).

However, data were obtained for a larger proportion of the patients at M24, presumably due to the greater effort made to contact participants and, if the participants themselves could not be contacted, their families. The availability of biological data, and thus knowledge about abstinence, was more limited as it was restricted to patients we were able to trace.

The differences between the population at inclusion and the population at M24 correspond to the difference in the proportion of subjects living alone $(35.2 \%$ at M0 and $37.7 \%$ at M24, $p<0.001$ ), being single/widowed or divorced ( $34.5 \%$ at M0 versus $31.3 \%$ at M24; $p<0.001$ ), having a professional activity (57.6 \% at M0 and $41.2 \%$ at M24, $p<0.001)$ and being on benefits $(71.4 \%$ at M0 versus $60.1 \%$ at M24, $p<0.001)$. Neither age $(45.2 \pm 10.2$ years versus $45.6 \pm 10.2$ years, $p=0.12)$ nor $\operatorname{sex}(78.7 \%$ men at M24 versus $78.2 \%$ at M0, $p=0.681)$ differed between M0 and M24.

A large number of subjects (21) died during the 24 months of the study.

Overall, the abstinent individuals did not follow a linear trajectory between M0 and M24. Data for all the follow-up visits were available for 87 people, 58 of whom (66.7 \%) displayed intermittent abstinence. Only $23 \%$ (20 participants) were entirely abstinent during the entire period from M0 to M24. Clinical data, but without biological data, were obtained for 281 participants; $24.6 \%$ (69 participants) declared a total absence of alcohol consumption over the entire 24-month follow-up, whereas $61.5 \%$ reported intermittent alcohol consumption.

The number of subjects remaining abstinent varied according to the criteria: clinical or biological. An analysis of the coherence of the two definitions of abstinence yielded a kappa value of 0.2307 , with a $95 \%$ confidence interval of $0.08-0.38$. These values indicate poor concordance between the two measures.

We considered all records of diagnoses of comorbid conditions at any time point during the care of the subject within the 24 months following alcohol withdrawal. Mood disorders were the most frequently reported. The type and nature of the psychiatric co-morbidities reported at M24 differed from those at M0 $(p<0.001)$ with significantly less subjects with mood disorders or anxiety disorders, but an equivalent proportion of psychotic disorders, suggesting that this category benefits from better insertion in the care system.

Few somatic comorbid conditions were reported during the follow-up. At the various follow-up visits, we recorded all diagnoses for diverse conditions requiring treatment and causing some disability (e.g., lower back pain) $(n=5)$, episodic conditions (2), viral infections including hepatitis (9), lung and ear diseases (2), metabolic problems (obesity) (1) and cirrhosis (1). The proportion of somatic conditions reported between $\mathrm{M} 0$ and M24 did not differ $(p=0.516)$.

The mean scores for the psychometric scales indicated an improvement in the general state of the participants from M6 onward. At each follow-up visit, we observed an improvement in GAF score $(p<0.01)$, a significant decrease in depression score $(p<0.001)$ and a significant decrease in alcohol dependence (AUDIT score; $p<0.001$ ) with respect to the values obtained at M0. The values obtained at the various follow-up visits (M6, M12, M18 and M24) did not differ for the population as a whole. In addition, the mean values of the biological markers used ( $\gamma \mathrm{GT}$ and $\mathrm{MCV}$ ) returned to normal during the followup, whereas they were outside this range at M0.

Before requesting assistance to stop drinking, the participants had been hospitalized more than four times on average (Table 3). Only $39 \%$ (129 participants) were admitted to a psychiatric unit for the first time when they requested assistance to stop drinking. Similarly, the mean duration of psychiatric care before the request for assistance was relatively short, although $19 \%$ of the patients had been receiving care for over 10 years. 
Table 2 Quantitative and qualitative variables collected at 6 (M6), 12 (M12), 18 (M18) and 24 (M24) months after alcohol withdrawal

\begin{tabular}{|c|c|c|c|c|c|c|c|c|}
\hline & \multicolumn{2}{|l|}{ M6 } & \multicolumn{2}{|l|}{ M12 } & \multicolumn{2}{|l|}{ M18 } & \multicolumn{2}{|l|}{ M24 } \\
\hline & Mean \pm SD or $\%$ & $N$ & Mean \pm SD or $\%$ & $N$ & Mean \pm SD or $\%$ & $N$ & Mean \pm SD or $\%$ & $N$ \\
\hline With any data & 51.8 & 171 & 38.6 & 146 & 42.7 & 141 & 51.8 & 249 \\
\hline With data to assess abstinence & 27.6 & 91 & 33.9 & 112 & 33.9 & 112 & 75.5 & 171 \\
\hline Abstinent & 57.1 & 52 & 40.2 & 45 & 46.4 & 52 & 41.4 & 103 \\
\hline \multicolumn{9}{|c|}{ Reasons for the absence of follow-up } \\
\hline No data—lost & 47.8 & 76 & 62.4 & 118 & 38.8 & 128 & 13.3 & 13 \\
\hline Impossible to come & 24.8 & 82 & 34.4 & 65 & 15.2 & 50 & 19.4 & 64 \\
\hline Death & 0.03 & 1 & 3.2 & 6 & 7.3 & 14 & 21.4 & 21 \\
\hline With a psychiatric comorbidity & 56.7 & 97 & 63.7 & 93 & 42.5 & 77 & 48.2 & 120 \\
\hline Type of psychiatric comorbidity & & & & & 37.7 & & & \\
\hline None & 29.9 & 29 & 42.0 & 39 & 5.19 & 29 & 46.7 & 50 \\
\hline Dementia & 0 & 0 & 0 & 0 & 15.5 & 4 & 0 & 0 \\
\hline Psychosis & 9.3 & 9 & 18.2 & 17 & 20.7 & 12 & 14.9 & 16 \\
\hline Mood disorder & 37.1 & 36 & 20.4 & 19 & 3.9 & 16 & 13.1 & 14 \\
\hline Anxiety disorder & 9.3 & 9 & 3.2 & 3 & 24.7 & 3 & 1.9 & 2 \\
\hline Personality disorder & 21 & 18 & 20.4 & 19 & & 19 & 15.9 & 17 \\
\hline With somatic comorbidity & 11.3 & 11 & 6.5 & 6 & 5.2 & 4 & 5.6 & 6 \\
\hline Global Assessment of Functioning & $59.9 \pm 19.7$ & 70 & $56.7 \pm 20.1$ & 66 & $59.7 \pm 20.6$ & 63 & $58.2 \pm 19.3$ & 88 \\
\hline AUDIT score & - & & $14.5 \pm 12.2$ & 130 & - & & $14.0 \pm 12.1$ & 162 \\
\hline Risk use (score $\leq 7$ ) & - & & 36.2 & 45 & - & & 40.1 & 65 \\
\hline Harmful use $(7<$ score $<13)$ & - & & 13.1 & 17 & - & & 6.2 & 10 \\
\hline Dependence (score $\geq 13$ ) & - & & 50.8 & 66 & - & & 50.6 & 82 \\
\hline $\mathrm{BDI}$ & $8.3 \pm 7.3$ & 163 & $7.8 \pm 7.5$ & 133 & $7.2 \pm 7.1$ & 130 & $7.7 \pm 7.3$ & 168 \\
\hline Absent & 29.5 & 48 & 39.1 & 52 & 36.9 & 48 & 40.2 & 68 \\
\hline Slight & 25.8 & 42 & 15.8 & 21 & 24.6 & 32 & 20.1 & 34 \\
\hline Moderate & 28.8 & 47 & 30.1 & 40 & 25.4 & 33 & 21.3 & 36 \\
\hline Severe & 15.9 & 26 & 15.0 & 20 & 13.1 & 17 & 18.3 & 31 \\
\hline MCV (UI/L) & $94.9 \pm 6.0$ & 175 & $95.4 \pm 5.9$ & 140 & $94.4 \pm 5.9$ & 141 & $94.3 \pm 6.2$ & 169 \\
\hline$\%>$ normal values $(n)$ & 34.9 & 61 & 40 & 56 & 30.5 & 43 & 34.3 & 58 \\
\hline $\mathrm{TGO}(\mathrm{UI} / \mathrm{L})$ & - & & - & & - & & $39.0 \pm 55.3$ & \\
\hline$\%>$ normal values $(n)$ & & & & & & & 24.6 & 41 \\
\hline TGP (UI/L) & - & & - & & - & & $38.8 \pm 61.9$ & \\
\hline$\%>$ normal values $(n)$ & & & & & & & 29.9 & 50 \\
\hline GGT (UI/L) & $94.9 \pm 6.0$ & 175 & $108.0 \pm 269.3$ & 143 & $112.9 \pm 290.8$ & 140 & $156.0 \pm 379.9$ & 168 \\
\hline$\%>$ normal values $(n)$ & 43.4 & 76 & 40.6 & 58 & 41.4 & 58 & 18.8 & 82 \\
\hline \multicolumn{9}{|l|}{ Current psychotropic treatment } \\
\hline Neuroleptics & 15.3 & 27 & 13.3 & 20 & 18.0 & 27 & 15.0 & 36 \\
\hline Atypical antipsychotics & 25.0 & 44 & 24.6 & 37 & 24.0 & 36 & 23.0 & 55 \\
\hline Thymoregulators & 13.6 & 24 & 12.0 & 18 & 12.0 & 18 & 11.3 & 27 \\
\hline Antidepressants & 63.0) & 111 & 65.3 & 98 & 62.6 & 94 & 51.8 & 124 \\
\hline Anxiolytics & 67.0 & 118 & 65.3 & 98 & 61.3 & 92 & 57.3 & 137 \\
\hline Benzodiazepines & 56.2 & 99 & 56.0 & 84 & 11.5 & 38 & 48.9 & 116 \\
\hline Related to benzodiazepines & 22.1 & 39 & 17.3 & 26 & 25.1 & 83 & 18.1 & 43 \\
\hline
\end{tabular}

AUDIT Alcohol Use Disorder Identification Test, BDI Beck Depression Inventory, GGT gamma-glutamyl transferase, MCV mean corpuscular volume, SGOT serum glutamate oxaloacetate transaminase, SGPT serum glutamic pyruvic transaminase 
Table 3 Psychiatric care before inclusion to the study (before alcohol withdrawal) and during the 24 months after alcohol withdrawal (between M0 and M24) $(n=330)$ [(mean \pm SD or \% (n)]

\begin{tabular}{|c|c|}
\hline \multicolumn{2}{|l|}{ Before alcohol withdrawal } \\
\hline Number of psychiatric hospitalizations & $4.4 \pm 8.3$ \\
\hline Duration of psychiatric care (years) & $4.5 \pm 7.1$ \\
\hline \multicolumn{2}{|l|}{ Between M0 and M24 } \\
\hline Cumulative number of days of complete hospitalization & $79.8 \pm 130$ \\
\hline Cumulative number of days of psychiatric home care & $52.4 \pm 71.9$ \\
\hline Rehospitalization & $56.2 \%(164)$ \\
\hline $\begin{array}{l}\text { Number of days between withdrawal and first psychi- } \\
\text { atric care }\end{array}$ & $146.4 \pm 162.8$ \\
\hline Home visits & $1.5 \pm 8.4$ \\
\hline
\end{tabular}

Almost half the participants were readmitted in the 24 months following withdrawal, whereas a quarter only had outpatient follow-up (23.6 \%). Patients returned to the care system relatively rapidly, with rehospitalization or the first care intervention within the first 6 months after weaning off alcohol. A total absence of care in the 24 months after weaning off alcohol was observed for only $7 \%$ of the participants (Table 3 ).

We further studied the psychiatric comorbid conditions and characteristics according to care data. Patients with psychiatric comorbid conditions attended more follow-up visits for this study than patients without such comorbid conditions. For example, 51.4 \% (90 participants) of subjects with comorbid conditions attended at least three follow-up visits, in comparison with only $32.3 \%$ (50 participants) of those without comorbid conditions $(p=0.011)$. The first care intervention was between M0 and M6 for $70.9 \%$ (124 participants) of subjects with comorbid conditions, but only $62.6 \%$ without comorbid conditions $(p<0.001)$. A total absence of treatment was observed for only $13.1 \%$ (23 participants) of subjects with comorbid conditions and $25.8 \%$ (40 participants) with no psychiatric comorbid condition.

We looked for an association between socio-demographic variables (age, sex, source of income, living alone) or care received during the 24-month follow-up (hospitalizations, outpatient care) with abstinence status at M24.

Following the univariate analysis of the study population, the five variables retained for the multivariate logistic regression were care category $(p=0.199)$, age $(p=0.015)$, sex $(p=0.033)$, living alone $(p=0.146)$ and private income $(p=0.118)$.

In the multivariate logistic model, age and sex were significantly associated with abstinence at 24 months, as older age was associated with a higher likelihood of abstinence at 24 months. Participants aged over 60 years were therefore six times more likely to be abstinent at the end of the 24-month follow-up than participants under the age of 30 years. Women were twice as likely as men to be abstinent after the 24-month follow-up (Table 4). At the end of the manual stepwise descending procedure for logistic regression, only age was still included in the adjusted model.

\section{Discussion}

Profile on inclusion

The study population was mostly male (78 \% men) and was therefore comparable to the populations in epidemiological studies carried out in the USA: the National Comorbidity Survey [24, 25] and the National Epidemiologic Survey on Alcohol and Related Conditions (NESARC cohort study) [26]. Marital status (69\% were single, divorced or widowed) differed significantly from that of the general population in the region $(32.5 \%$ single, $7 \%$ divorced, $10.5 \%$ widowed, corresponding to $50 \%$ [27]. Insertion in the workplace was better than expected for individuals requesting care in a psychiatric unit, because psychiatric problems are known to be a factor favoring employment loss and a low likelihood of returning to work [28]. However, the cohort employment rate $(55.4 \%)$ was lower than that of the general population in Limousin (70 \% of 15- to 49 -year-olds and $51 \%$ of 50- to 64-year-olds work) [29] or in France (65.1\% of the French population was in paid work in March 2008, and the current proportion is $64.1 \%$ ). The GAF score [30], which measures overall functioning, improved over the 24-month follow-up.

The AUDIT score has a considerably valuable number of features for the routine diagnosis of risky or dangerous alcohol consumption. However, it is less relevant for follow-up as it was designed as a screening test [20]. Nevertheless, at least three of the items, those concerning the frequency of alcohol consumption, total alcohol consumption and the number of heavy drinking days (at least six units) decreased between M0 and M24 in our study, for subjects with high consumption levels at M0. This is particularly relevant as decreases of only a few units for "heavy drinkers" have been shown to have an exponential effect on damage reduction [31].

The mean BDI score for the cohort was high for a population not included on the basis of depressive illness. However, this scale only evaluates the intensity of symptoms associated with depression and has no diagnostic value.

Depressive mood is very frequent immediately after alcohol withdrawal, potentially due, at least in part, to the high frequency of depressive symptoms in this population. The decrease in BDI depression scores for all patients after 6 months of follow-up reflects the positive consequences of a decrease in alcohol consumption 
Table 4 Odds ratios (OR) unadjusted and adjusted (logistic regression) for the association of age and gender to abstinence at 24 months after alcohol withdrawal

\begin{tabular}{|c|c|c|c|c|c|c|}
\hline \multirow{3}{*}{$\begin{array}{l}\text { Effect } \\
\text { Ambulatory care }\end{array}$} & \multicolumn{3}{|l|}{ Unadjusted } & \multicolumn{3}{|l|}{ Adjusted } \\
\hline & \multirow{2}{*}{$\begin{array}{l}\text { Odds ratio } \\
0.93\end{array}$} & \multicolumn{2}{|c|}{$95 \%$ confidence interval } & \multirow[t]{2}{*}{ Odds ratio } & \multicolumn{2}{|c|}{$95 \%$ confidence interval } \\
\hline & & 0.36 & 2.42 & & & \\
\hline Hospitalization & 0.58 & 0.25 & 1.37 & & & \\
\hline Age $<60$ & 2.10 & 0.66 & 6.66 & 2.10 & 0.66 & 6.66 \\
\hline Age $>60$ & 7.58 & 1.74 & 33.09 & 7.58 & 1.74 & 33.09 \\
\hline Gender female/male & 1.98 & 1.06 & 3.70 & & & \\
\hline Living alone & 0.67 & 0.39 & 1.15 & & & \\
\hline Own resources & 1.59 & 0.89 & 2.84 & & & \\
\hline
\end{tabular}

on depressive symptoms [5, 32]. More than half the participants presented a dual diagnosis of AUD and another psychiatric problem. The frequency of psychiatric problems among alcohol-dependent patients in the general population has already been shown to be high [33-35] and is even higher in hospitalized populations [36]. This may reflect the greater demand for assistance to stop drinking by patients with comorbid conditions, otherwise known as Berkson's bias [37, 38]. This effect was amplified in our study by the recruitment of participants from a psychiatric hospital environment. In our study population, depression was the most frequent comorbid psychiatric condition, ahead of psychotic, anxious and bipolar disorders, both at inclusion and after 24 months. Some of the patients initially diagnosed as having depression in this cohort may actually have had bipolar depression, and this might result in a need to readjust the diagnoses during the follow-up period. Previous studies have highlighted the difficulties associated with these diagnoses in alcohol-dependent patients [39, 40].

Most studies have shown that depressive symptoms are frequent in people with AUD, but that characterized depressive episodes are rare. These transient symptoms of depression not fulfilling the criteria for diagnosis of a major depressive episode disappear after 1-2 weeks of abstinence $[41,42]$ and should not lead to treatment with an antidepressant unless they persist for much longer [15].

The high death rate of $6.4 \%(21 / 330)$ among the patients seeking a cure for alcohol dependence during the survey can be emphasized. The absolute risk of dying from an adverse alcohol-related condition increases linearly with the amount of alcohol consumed over a lifetime [43]. The annual absolute risk of dying from an alcoholrelated disease for people aged over 15 years across the population in the World Health Organization (WHO) European Region is around 0.1 for a daily consumption of over $70 \mathrm{~g}$. In 2012, $5.9 \%$ of all global deaths were attributable to alcohol, with the highest proportion in the WHO European Region [43].

Finally, we observed an increase in the prevalence of psychiatric problems during the course of the study, potentially corresponding to an initial underestimation of comorbid psychiatric conditions and the occurrence of new clinical episodes of psychiatric conditions during the 2 -year follow-up period [1,24, 25]. The clinical subpopulation with a dual diagnosis of AUD and a psychiatric problem should be studied in greater detail, because such dual diagnoses have been shown to be associated with a poorer prognosis for both conditions [14, 33, 34, 44].

\section{Abstinence and changes during the 24 months following the request for assistance to stop drinking}

Overall, $41.4 \%$ of the subjects were still abstinent at 24 months. However, focusing solely on abstinence at this last time point (M24) does not provide an entirely satisfactory evaluation of the success of the intervention. Our results also raise questions regarding the criteria used to evaluate abstinence. The use of a combination of clinical and biological criteria for abstinence makes it possible to optimize the detection of "false abstinent" individuals. However, in practice, these criteria may be too strict, potentially masking real differences. The use of abstinence as the only criterion for evaluating care in the treatment of patients with AUD is now seen as somewhat heavy handed. Decreasing consumption also seems to be a beneficial objective, with the aim of decreasing morbidity and mortality [45-47]. Finally, old age (over the age of 60 years) and being female were the only criteria significantly linked to successful weaning off alcohol after 24 months in our study. However, this finding should be interpreted with caution given the small proportions of women and subjects over the age of 60 years in our study population. Nevertheless, these individuals may constitute subgroups of the population with more difficult 
access to care for AUD and, thus, with probably a much greater motivation to succeed.

The request for help to stop drinking is part of a long, very personal process. It is invariably preceded by a long progressive phase that is not sufficient in itself to create the conditions required for sustained abstinence. This process involves alternating periods of alcohol consumption and partial or complete abstinence, sometimes linked to identifiable factors, but above all to conflicts and internal thought processes.

Sustaining medium- and long-term abstinence seems to be directly linked to the attention devoted to the addiction problem, the psychiatric conditions with which it is comorbid and the quantity and pertinence of care delivered $[33,48]$. Patients with comorbid psychiatric conditions were more compliant in this study. This may have been due to their stronger demand for help or prior integration in a follow-up system, thereby facilitating follow-up for this study. This was the case, for example, for patients with schizophrenia and AUD. For the patients, the follow-up was part of the care process. It has also been reported that patients with a dual diagnosis make greater use of care facilities [49], including emergency services [16]. In the context of care rationalization, changes in the use of care facilities over time should be considered in more detail. In contrast, few of the interventions by psychologists and social workers took place in the patients' homes, presumably reflecting the largely institutional and medical management of AUD in France. The results provided here give an evidence of the patients-institution interaction, which does not appear to be so intensive and tightened.

Antidepressant use was high (52.7 \%). In France, recommendations are to wait for 2-4 weeks after weaning off alcohol before introducing antidepressant treatment, unless the symptoms are acute and intense with a risk of suicidal behavior. Furthermore, benzodiazepines, which are authorized for use as anxiolytics for short periods of no longer than 12 weeks, should not be prescribed for longer than the standard duration of the weaning period, which is of the order of about 10 days at most [50]. It can be highlighted that the investigators were not given any instructions regarding the type of therapeutics to use during the survey (either pharmacological or non-pharmacological) because of the semi-naturalistic nature of the study,

\section{Bias}

The results obtained in this study were collected for a specific population: chronic alcohol consumers who had contacted the hospital's psychiatric department. Overall, $20.30 \%$ of the patients were lost to follow-up at M24, but not all the patients attended all the follow-up visits. This limited the sample size, with deleterious consequences for the statistical analysis. Indeed, this study was seminaturalistic in design, with data collection based largely on the integration of participants in a care pathway that varied from patient to patient. Nevertheless, we consider this one of the strengths of the cohort, as it includes strict evaluations linked to the study of a fate more compatible with a patient-focused care pathway for subjects requesting help from the psychiatric care system to stop drinking.

\section{Conclusion}

In this observational cohort study of 330 patients requesting assistance from the psychiatric care system to stop drinking, we found that only $25 \%$ of the participants remained abstinent throughout the entire 24-month follow-up, with $41.4 \%$ of the participants considered abstinent after 2 years; $66.7 \%$ of the participants displayed intermittent abstinence over the 2-year follow-up period. Some sub-groups may be defined with regard to their chance of abstinence and further characterization may be helpful in the routine practice. However, patients with a comorbid psychiatric condition underwent a larger number of follow-up visits for the study, together with a larger number of treatment sequences and health-care interventions. The lack of agreement between clinical and biological data for abstinence and the other results obtained suggest that studies of combined markers or prognosis, biopsychosocial outcome and fate after weaning are required. These findings also confirm the importance of not focusing solely on short-term management and abstinence.

\section{Abbreviations \\ AUD: alcohol use disorders; AUDIT: Alcohol Use Disorders Identification Test; BDI: Beck Depression Inventory scale; DSM-IV-TR: Diagnostic And Statistical Manual of Mental Disorders IV Revised; $ү G T$ : gamma-glutamyl transferase; GAF: Global Assessment of Functioning; HDD: heavy drinking days; MCV: mean corpuscular volume; SGPT: serum glutamic pyruvic transaminase; SGOT: glutamate oxaloacetate transaminase; TAC: total alcohol consumption; WHO: World Health Organization.}

\section{Authors' contributions}

PN drafted the manuscript. MG designed the study and organized the coordination and participated in the statistical analysis. DM conceived the study, participated in its design and coordination and helped to draft the manuscript. $\mathrm{BM}$ conducted the statistical analysis. All authors read and approved the final manuscript.

\section{Author details \\ 1 Pôle Addictologie, Centre Hospitalier Esquirol, 15 rue du Dr Marcland, 87025 Limoges, France. ${ }^{2}$ Département de Recherche et Développement (DRD), Centre Hospitalier Esquirol, 87025 Limoges, France. ${ }^{3}$ Faculté de Méde- cine, UMR/INSERM1094, 2 rue du Dr Marcland, 87025 Limoges, France. ${ }^{4}$ Pôle de Psychiatrie Infanto Juvénile, Centre Hospitalier Esquirol, 87025 Limoges, France. ${ }^{5}$ Pôle de Psychiatrie Adulte, Centre Hospitalier Esquirol, 87025 Limo- ges, France.}

\section{Acknowledgements}

The authors thank I. Alamome, K. Ampayrat, M. Arthus, Y. Auroux, V. Baloutch, N. Baloutch, L. Beauseigneur, M. F. Berthier, I. Boghina, V. Bouby-serieys, M. Bricaud, M. Bouchareychas, B. Calvet, G. Chandon, E. Charles, C. Chevalier, C. 
Ciobanu, J. P. Clement, H. Couvillers, A. Delage, L. Dominique, M. Drouffe, A.C. Dumond, C. Dumont, J. J. Dumont, P. Fayol, D. Fontanier, T. Fouli, L. Laot, S. Lesage, F. Lescure, E. R. Lombertie, A. Machemy, P. Malaganne, F. Meissonnier, M. P. Mellin, D. Meriochaud, A. Meynard, G. Monnier, B. Planson, C. Rainelli, A. Ratti, M. Renaud, V. Rouyer, N. Salome, P. Sazerat, D. Schadler D, J. L. Souchaud, A. M. Trarieux, G. Verger, P. Villeger, D. Walocha and Z. Zabraniecki for their assistance in patient inclusion and data collection.

\section{Competing interests}

The authors declare that they have no competing interest for this study. They are all employed at the Esquirol Hospital Center.

\section{Funding}

This work was supported by the French Health and Solidarity Minister in the frame of the clinical research hospital program 2006, and the Esquirol Hospital Center of Limoges, France.

\section{Availability of data and supporting materials}

Data are available upon request to the corresponding author.

Received: 30 November 2015 Accepted: 21 August 2016 Published online: 31 August 2016

\section{References}

1. Management of Substance Abuse Unit (MSB) and Department of Mental Health and Substance Abuse (MSD) of the World Health Organization (WHO). Global status report on alcohol and health. Chapter 3 health consequences, pp. 45-58. 2014. http://www.who.int/substance_abuse/ publications/global_alcohol_report/en/. Accessed 30 Nov 2015.

2. Hasin DS, Stinson FS, Ogburn E, Grant BF. Prevalence, correlates, disability, and comorbidity of DSM-IV alcohol abuse and dependence in the US: results from the National Epidemiologic Survey on Alcohol and Related Conditions. Arch Gen Psychiatry. 2007;64:830-42

3. Pirkola SP, Poikolainen K, Lönnqvist JK. Currently active and remitted alcohol dependence in a nationwide adult general population-results from the Finnish Health 2000 study. Alcohol Alcohol. 2006;41:315-20.

4. Hoertel N, Crochard A, Rouillon F, Limosin F. L'alcool en France et ses conséquences médicales et sociales: regard de l'entourage et des médecins généralistes. Encephale. 2014;40:S11-31.

5. Pickering P. Conduites d'alcoolisation et pathologies psychiatriques. In: Reynaud M, editor. Traité d'addictologie. Paris: Médecine Sciences Flammarion; 2006. p. 340-9.

6. Acquaviva E, Beaujouan L, Nuss P, Chaput JC, Chieze F. Prévalence de l'abus d'alcool dans un hôpital de l'AP-HP = Prevalence of alcohol abuse in a French public hospital. Alcoologie et Addictologie. 2003;25:201-7.

7. Guérin S, Laplanche A, Dunant A, Hill C. Alcohol-attributable mortality in France. Eur J Pub Health. 2013;23:588-93.

8. Le Lukasiewicz M. double diagnostic en addictologie: état des lieux et prise en charge. In: Reynaud M, editor. Traité d'addictologie. Paris: Médecine Sciences Flammarion; 2006. p. 95-102.

9. About the family and marital status in Limousin in 2010. INSEE (National Institute of Statistics and Economic Studies) data. 2011. http://Www.insee. fr/fr/insee_regions/limousin/themes/dossiers/tel-2010/tel_2010_2_3.pdf. Accessed 22 Dec 2014.

10. Anderson P, Møller L, Galea G, Shield KD, Kehoe Chan TAK, Gmel G, et al. Consumption, harm and policy approach. In: Anderson P, Moller L, Gadea $\mathrm{G}$, editors. Alcohol in the European Union. Copenhagen: World Health Organization Office; 2012. p. 1-101.

11. Beck F, Dervaux A, Du Roscoät E, Gallopel-Morvan K, Grall-Bronnec, Kern $L$, et al. Principaux constats et recommandations. Expertise collective. In: Institut National de la Santé et de la Recherche Médicale, editor. Conduites addictives chez les adolescents. Usages, Prévention et accompagnement. Paris: INSERM. 2014. p. 1-54.

12. Hoertel N, Crochard A, Limosin F, Rouillon F. La consommation excessive d'alcool: un lourd fardeau pour l'entourage. Encephale. 2014;40:S1-10.

13. Clark BJ, Keniston A, Douglas IS, Beresford T, Macht M, Williams A, Jones J, Burnham EL, Moss M. Healthcare utilization in medical intensive care unit survivors with alcohol withdrawal. Alcohol Clin Exp Res. 2013;37:1536-43.
14. Lejoyeux M, Marinescu M. Alcool et comorbidité psychiatrique. Rev Prat. 2006;56:1081-5.

15. Suter M, Strik W, Moggi F. Depressive symptoms as a predictor of alcohol relapse after residential treatment programs for alcohol use disorder. J Subst Abuse Treat. 2011;41:225-32.

16. Wohl M, Ades J. Dépression et addictions: quels liens et quelle séquence thérapeutique? Rev Prat. 2009;59:484-7.

17. Swartz MS, Swanson JW, Hiday VA, Borum R, Wagner HR, Burns BJ. Violence and severe mental illness: the effects of substance abuse and nonadherence to medication. Am J Psychiatry. 1998;155:26-31.

18. Dickey B, Azeni H. Persons with dual diagnoses of substance abuse and major mental illness: their excess costs of psychiatric care. Am J Public Health. 1996;86:973-7.

19. Rouchaud A. Les addictions en Limousin—Etat des Lieux (Addictions in Limousin-State places). Observatoire Régional de Santé du Limousin (Regional Observatory of Limousin Health). 2014. http://www.orslimousin.org. Accessed 22 Dec 2014.

20. Saunders JB, Aasland OG, Babor TF, de la Fuente JR, Grant M. Development of the alcohol use disorders identification test (AUDIT): WHO collaborative project on early detection of persons with harmful Alcohol consumption-II. Addiction. 1993;88:791-804.

21. Beck AT, Ward CH, Mendelson M, Mock J, Erbaugh J. An inventory for measuring depression. Arch Gen Psychiatry. 1961;4:561-71.

22. Beck AT, Steer RA, Carbin MG. Psychometric properties of the Beck Depression Inventory: twenty-five years of evaluation. Clin Psychol Rev. 1988:8:77-100.

23. McPherson A, Martin CR. A narrative review of the Beck Depression Inventory (BDI) and implications for its use in an alcohol dependent population. J Psychiatr Ment Health Nurs. 2010;17:19-30.

24. Alonso J, Angermeyer MC, Bernert S, Bruffaerts R, Brugha TS, Bryson H, ESEMeD/MHEDEA 2000 Investigators. European Study of the Epidemiology of Mental Disorders (ESEMeD) Project. 12-Month comorbidity patterns and associated factors in Europe: results from the European Study of the Epidemiology of Mental Disorders (ESEMeD) project. Acta Psychiatr Scand Suppl. 2004;420:28-37.

25. Kessler RC, Crum RM, Warner LA, Nelson CB, Schulenberg J, Anthony JC. Lifetime co-occurrence of DSM-III-R alcohol abuse and dependence with other psychiatric disorders in the National Comorbidity Survey. Arch Gen Psychiatry. 1997;54:313-21.

26. Grant BF, Stinson FS, Dawson DA, Chou SP, Ruan WJ, Pickering RP. Cooccurrence of 12-month alcohol and drug use disorders and personality disorders in the US: results from the National Epidemiologic Survey on Alcohol and Related Conditions. Arch Gen Psychiatry. 2004;61:631-8.

27. INSEE (National Institute of Statistics and Economic Studies) data. About the Limousin population and its characteristics. .http://www.insee.fr/fr/ regions/limousin/reg-dep.asp?theme=2\#tableau. Accessed 22 Dec 2014.

28. Claussen B. Alcohol disorders and re-employment in a 5-year follow-up of long-term unemployed. Addiction. 1999;94:133-8.

29. Bonneau I. En Limousin, les seniors occupant un emploi sur quatre. In: Institut National de la Statistique et des Etudes Economiques, editor. Focal_INSEE Limousin 71. Limoges: INSEE; 2011. p. 1-4.

30. Pedersen $G$, Karterud $S$. The symptom and function dimensions of the Global Assessment of Functioning (GAF) scale. Compr Psychiatry. 2012;53:292-8.

31. Global status report on alcohol and health. Poznyak and Rekve, editors. Geneva: World Health Organization. http://www.who.int/substance_ abuse/publications/global_alcohol_report/en/. Accessed 22 Dec 2014

32. Dackis CA, Gold MS, Pottash AL, Sweeney DR. Evaluating depression in alcoholics. Psychiatry Res. 1986;17:105-9.

33. Blonigen DM, Burroughs T, Haber JR, Jacob T. Psychiatric morbidity is linked to problem drinking in midlife among alcohol-dependent men: a co-twin control study. J Stud Alcohol Drugs. 2013;74:136-40.

34. Carrà G, Johnson S, Bebbington P, Angermeyer MC, Heider D, Brugha $T$, et al. The lifetime and past-year prevalence of dual diagnosis in people with schizophrenia across Europe: findings from the European Schizophrenia Cohort (EuroSC). Eur Arch Psychiatry Clin Neurosci. 2012;262:607-16

35. Regier DA, Farmer ME, Rae DS, Locke BZ, Keith SJ, Judd LL, et al. Comorbidity of mental disorders with alcohol and other drug abuse. Results from the epidemiologic catchment area (ECA) study. JAMA. 1990;264:2511-8. 
36. Weaver T, Madden P, Charles V, Stimson G, Renton A, Tyrer P, Comorbidity of Substance Misuse and Mental IIIness Collaborative study team, et al. Comorbidity of substance misuse and mental illness in community mental health and substance misuse services. Br J Psychiatry. 2003;183:304-13.

37. Berkson J. Limitations of the application of fourfold table analysis to hospital data. Biom Bull. 1946;2:47-53.

38. Rounsaville BJ, Dolinsky ZS, Babor TF, Meyer RE. Psychopathology as a predictor of treatment outcome in alcoholics. Arch Gen Psychiatry. 1987;44:505-13.

39. Albanese MJ, Clodfelter RC Jr, Pardo TB, Ghaemi SN. Underdiagnosis of bipolar disorder in men with substance use disorder. J Psychiatr Pract. 2006;12:124-7.

40. Angst J, Gamma A, Endrass J, Rössler W, Ajdacic-Gross V, Eich D, et al. Is the association of alcohol use disorders with major depressive disorder a consequence of undiagnosed bipolar-ll disorder? Eur Arch Psychiatry Clin Neurosci. 2006;256:452-7.

41. Lejoyeux M, Boulenguiez S, Fichelle A, McLoughlin M, Claudon M, Adès J. Alcohol dependence among patients admitted to psychiatric emergency services. Gen Hosp Psychiatry. 2000;22:206-12.

42. Schuckit MA, Tipp JE, Bergman M, Reich W, Hesselbrock VM, Smith TL. Comparison of induced and dependant major depressive disorders in 2945 alcoholics. Am J Psychiatry. 1997;154:948-57.

43. Anderson P, Moller L, Gadea G, Schield K, Kehoe-Chan T, Gmel G, et al. Alcohol in the European Union. Consumption, harm and policy approach. Copenhagen:WHO Regional Office for Europe. http://www. euro.who.int/_data/assets/pdf_file/0003/160680/e96457.pdf. Accessed 30 Nov 2015.
44. Hashimoto E, Tayama M, Ishikawa H, Yamamoto M, Saito T. Influence of comorbid alcohol use disorder on treatment response of depressive patients. J Neural Transm (Vienna). 2015;122:301-6.

45. Gual A, He Y, Torup L, van den Brink W, Mann K, ESENSE 2 Study Group. A randomised, double-blind, placebo-controlled, efficacy study of nalmefene, as-needed use, in patients with alcohol dependence. Eur Neuropsychopharmacol. 2013;23:1432-42.

46. Heather N, Partington S, Partington E, Longstaff F, Allsop S, Jankowski M, et al. Alcohol use disorders and hazardous drinking among undergraduates at English universities. Alcohol Alcohol. 2011;46:270-7.

47. Pilling S, Yesufu-Udechuku A, Taylor C, Drummond C, Guideline Development Group. Diagnosis, assessment, and management of harmful drinking and alcohol dependence: summary of NICE guidance. BMJ. 2011;342:d700.

48. Agyapong VI, Ahern S, McLoughlin DM, Farren CK. Supportive text messaging for depression and comorbid alcohol use disorder: single-blind randomised trial. J Affect Disord. 2012;141:168-76.

49. Curran GM, Sullivan G, Williams K, Han X, Collins K, Keys J, et al. Emergency department use of persons with comorbid psychiatric and substance abuse disorders. Ann Emerg Med. 2003;41:659-67.

50. ANAES (Agence Nationale d'Accréditation et d'Evaluation en Santé) (National Agency for Accreditation and Evaluation in Health) data. Recommendation texts $<<$ Objectifs, indications et modalités du sevrage du patient alcoolodépendant $>>$ (Objectives, indications and patient withdrawal alcohol-dependent manner). 1999. http://www.has-sante.fr/ portail/jcms/c_272073/fr/objectifs-indications-et-modalites-du-sevragedu-patient-alcoolodependant. Accessed 9 Dec 2014.

\section{Submit your next manuscript to BioMed Central and we will help you at every step:}

- We accept pre-submission inquiries

- Our selector tool helps you to find the most relevant journal

- We provide round the clock customer support

- Convenient online submission

- Thorough peer review

- Inclusion in PubMed and all major indexing services

- Maximum visibility for your research

Submit your manuscript at www.biomedcentral.com/submit
() BioMed Central 